\title{
Exploring the Technical Issues Affecting Engineering Laboratories Design in Saudi Arabia
}

\author{
Mostafa A-B Ebrahim ${ }^{1,3}$, Mohamed F. Soliman ${ }^{2,4}$, M. H. Abdel-Aziz ${ }^{2,5}$ \\ ${ }^{1}$ Faculty of Engineering, King Abdulaziz University, Saudi Arabia (KSA) \\ ${ }^{2}$ Faculty of Engineering, King Abdulaziz University, Rabigh 21911, Saudi Arabia (KSA) \\ ${ }^{3}$ Civil Engineering Department, Faculty of Engineering, Assuit University, Egypt \\ ${ }^{4}$ Civil Engineering Department, Faculty of Engineering, Aswan University, Egypt \\ ${ }^{5}$ Chemical Engineering Department, Faculty of Engineering, Alexandria University, Egypt
}

\begin{abstract}
Well designing of laboratories will encourage industries to collaborate with the institute. Taking into consideration the requirements of the users and the lab administrators, this paper will explore the technical issues that affectdesigning a quality laboratory facility for an engineering faculty. Many technical factorson which customized engineering laboratories design pertinent to the needs and requirements of the end users and lab administrators are thoroughly assessed and analyzed before proposing an action plan to construct or develop a laboratory for the Faculties of Engineering. A consensus by the members of the research committee, after thorough considerations and analysis of the type of problem in hand, is met, wherein it is agreed upon that despite differences in individual lab projects, certain commonalities do exist in successful laboratory establishment. Among the critical ingredients are the right personnel and their continuity; a thorough, thoughtful, and clearly defined course of action; and a broad understanding of the pertinent issues at hand. Among the various issues of importance, technical issues - is considered common to most types of laboratory facilities. Technical issues, despite appearing to be common sense, bear great importance to the proper management of any establishment process and hence need due consideration. This study serves as a guide to the scientific community, lab administrators, researchers etc. interested in establishing engineering laboratories according to their requirements particularly in Saudi Arabia but can be extended to be followed elsewhere.
\end{abstract}

Keywords: Engineering Laboratory; Design; Technical Issues; Saudi Arabia.

\section{Introduction}

Technically sophisticated facilities that house laboratories are complex and intense mechanical structures[1], [2], [4], and [5]; therefore, they are costly to erectand maintain[7] and [11]. Laboratory facility design is therefore challenging tasks for all concerned parties[16], [17], [18], [20], and [22. Many key decisions need to be made before and during new construction of a laboratory facility[23], [30], [10], [21], and [25]. Successful functioning of the facility upon completion and the ease and success with which it can be maintained after being put into service will be determined by these critical decisions[32], [34], and [35]. Ironically, many of these important selections and choices are forced onto lab users and/or lab administrators who, at project initiation, have minimum knowledge of design of laboratory facilities so their knowledge base must be quickly increased[8], [3], [12], [37], and [38]. The existing literature on the subject, however, is targeted towards the professional design community, most of whom are familiar with the issues and processes of general design and construction[24], [9], and [28]. There is a dire need for basic as well as laboratoryoriented information focused towards the lab user community such as, the research scientists and lab administrators (because they are the ones who engage with the architects), engineers, and laboratory designers who plan and model the laboratory facility and the construction team who eventually build it[29], [33], and [36].
This work is focused towards the lab users; the research scientists, academic faculty, and the lab administrators and hence investigates on the technical factors affecting on the design of anefficacious laboratory facility rather than on the detailed specifications of a successful laboratory construction. Thus, a successful laboratory facility may be defined as the one that provides flexible and effective laboratories while being safe for its users and compatible with the surrounding environment. It must also have the support of the local community and concerned governmental and regulatory agencies, and, crucially, must be viable to be constructed in an economically feasible and cost-effective manner. Basic aspects of technical factors affecting the design projects will be discussed through this work. The general principles expounded by the research team make the propositions suitable to be applied to any laboratory facility design project. By means of investigations, the research team realized that despite differences in individual lab projects, certain commonalities do exist in successful laboratory establishment projects. Among these commonalities are the right personnel and their continuity; a thorough, thoughtful, and clearly defined process; and a comprehensive knowledge of the pertinent issues at hand. The common themes mentioned above are separately classified and discussed in technical issues. Other themes are more laboratory facility specific[26], [27], [13], and [14].

Four critical factors transcending specific issues have been identified by the research team as characteristics of

Volume 9 Issue 6, June 2020 


\section{International Journal of Science and Research (IJSR) \\ ISSN: 2319-7064}

ResearchGate Impact Factor (2018): 0.28 | SJIF (2019): 7.583

successful laboratory facility design projects[19], [15], and [6]:

1) Champion - someone totally committed to project success and one who has the faith of the client group while staying with the project from start to finish;

2) Design professional - usually a competent architect experienced in successful design and construction of laboratory facilities;

3) Process - clearly defined and structured process to implement the project all the way from pre-design through post-construction; and

4) Communication- horizontal and vertical communication having clear lines of responsibility and authority throughout the project for all involved participants.

All the above factors must be given due attention in order to achieve a successfully designed laboratory facility.

\section{Research Objective}

The objective of this research is toexplore the technicalfactorsthat have an influence on the approaches for the designof laboratory facilities for faculties of engineering in Saudi Arabian universities. Through this research, an attempt to explore and propose facilitating guidelines of technical issues that will aid in the design of a new laboratory facility has been made. These guidelines will assist in assuring the setup of flexible and efficient laboratories while being safe for laboratory users, having compatibility with the surrounding environment as well as having the support of the surrounding local community and concerned governmental organizations, and, crucially, can be effectively constructed in an economically feasible manner.

\section{Methodology}

The establishment of an engineering laboratory has a profound effect on the students and researchers of a specific department or field of study. To meet the requirements of design of anengineering laboratoryaccording to the needs of the end users and lab administrators, focus and emphasis is given to the analysis of the technical issues - in a typical laboratory development research.

\section{Exploring Technical Issue Affecting the Design of Labs in Faculties of Engineering}

Well-equipped and organized laboratories are a necessary component of any technical institute, especially of engineering colleges, and are earnestly required to impart quality education. Developed and established laboratories will not only help in providing the users - researchers, faculty members and students - with the necessary tools to conduct research and academic experiments but also to invite industries to collaborate with the institute. To this end, this paper is undertaken to suggest appropriate actions and effective approaches in exploring the technical factors affectingthe design of quality laboratory facility for the Faculties of Engineering, not on the details of laboratory construction per se. There are specific common elements in successful laboratory establishment projects. Technical
Issues are considered common to most of the types of laboratory facilities.

Some of the technical issues related to laboratory construction or renovation and their details are complex and highly specialized and hence should be left to be handled by experts, especially those issues that are governed by EH\&S regulations. Other issues such as design alternatives or factors affecting construction costs need to be reviewed, discussed, and resolved mutually by cooperation between members of the client group which include the client team, the user representative and the design professional. Therefore, in order to make informed and well-acquainted decisions, the client team and the user representative ought to be familiar with these issues. An informed and wellacquainted client who is abreast of the technical issues involved, can not only interact adequately and competently with the design professional, but knowledge of the design considerations also enables the client to evaluate the ability and competence of the design professional in a better manner.

The technical issues are concerned with highlighting the basic elements (codes) that ought to be factored in the design, construction, or renovation of a laboratory facility. These include, but are not limited to, the following:

a) Health of all users and surrounding community,

b) Safety of all employees and staff,

c) Environmental considerations to ensure adherence to all relevant codes and regulations,

d) Building codes and regulations,

e) Design details and feasibility issues, and

f) Cost and economic considerations.

To address the above listed issues and others, the following must be considered:

a) Designate an environmental health \& safety (EHS) advisor

b) Establish communications with regulatory authorities

c) Consider design alternatives

d) Complete pre-design before committing to a budget

e) Obtain cost estimates

f) Set adequate contingencies

\subsection{EnvironmentalHealthandSafety $(\mathrm{EH} \& S)$}

From the beginning to the end of all the phases -planning, design, and construction - of a laboratory construction or renovation project, meticulous thought and consideration to $\mathrm{EH} \& \mathrm{~S}$ issues is imperative to warrant that the laboratory facility can be built whilst ensuring it is suitable for occupation. Environmental, health and safety issues impact every major decision and choice from selection of the site to the suitabilityof the premisesfor occupancy by ensuring a safe and healthy environment for those who will utilize the laboratory facility. Also, cautious careful scrutiny and thought to these issues is paramount in communication with the neighboring local community, which may be avidly and fervently apprehensive about the impact of the laboratory facility to the locality.

Meticulous deliberation of environmental, health and safety issues will facilitate the project team to act in accordance with the highly complex and occasionally conflicting range

\section{Volume 9 Issue 6, June 2020}




\section{International Journal of Science and Research (IJSR) \\ ISSN: 2319-7064}

ResearchGate Impact Factor (2018): 0.28 | SJIF (2019): 7.583

of local regulations, codes, and ordinances that have an effect on the construction and functioning of laboratories. It is critical to identify that the codes and regulations governing the construction, renovation, and operation of laboratories and the undertaking of a building project by an institution have a universal goal to assurethat the building and the environment surrounding it will be safe for everyone concerned.

\subsubsection{Codes and regulations}

Construction or renovation of a laboratory building is regulated primarily by laws charted out by the municipality and the emirate in which the facility will be located. These laws incorporate, by reference, generally accepted standard practices set out in uniform codes. Figure1lists the typesof codes that concern most constructionprojects for laboratory facilities. The codes are usually administered at a municipal level but some locations may be administered at the emirate level. Scheduling theprocurement of requisite permits for construction will ensure the avoidance of preventable delays in the development project.

It is essential to provideagencies that grant permits early notification of major construction projects within their area ofjurisdiction so that they can predict and plan requisite work and human resource needs.

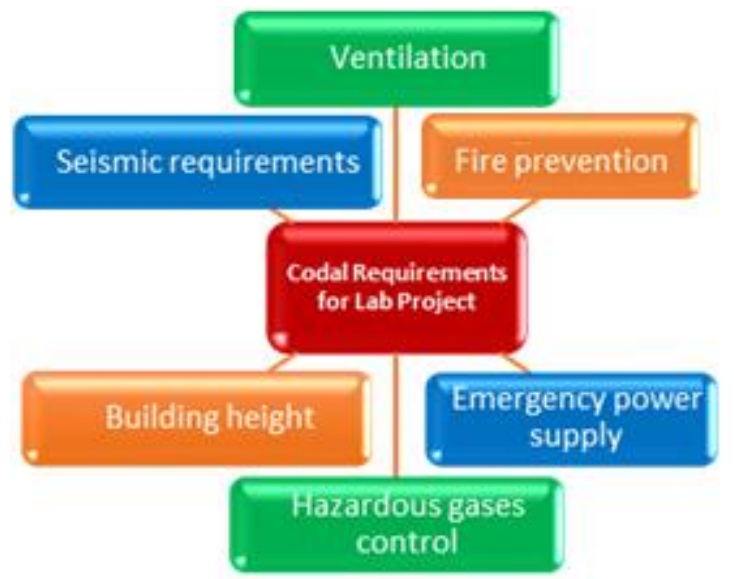

Figure 1: Code Requirements Affecting Laboratory Construction Projects

In certain jurisdictions, optimized communication is enabled by settingup a single point of contact between the agency and representatives of the project team - the clientand architect project managers -to facilitate and coordinate the exchange of critical information and to set up a healthy working relationship. An agency can quickly move through the required approval and permit granting process if it has lucid and adequate information about a complicated research or laboratory facility construction project prior to submission of actual plans.

Normally, a construction project must conform tobuilding, fire, mechanical, electrical, and plumbing standards and codes at the local level that may be regulatoryor performance based. Local codes often comply with internationally recognized standards developed by organizations such as the National Fire Protection Association (NFPA), the American National Standards Institute (ANSI), the American Society for Testing and
Materials (ASTM), and the American Society of Heating, Refrigeration, and Air-conditioning Engineers (ASHRAE) as well as the local Saudi Standards, Metrology and Quality Organization (SASO) - all of which tend to be revised as they evolve over time.

A summary list of the Saudi standards can be found on SASO web page (www.saso.gov.sa).

Besides the Saudi Building Code, three American code organizations - the International Conference of Building Officials (ICBO), the Building Officials and Code Administrators International (BOCA), and the Southern Building Code Congress International (SBCC) - were drafted to form a Uniform Building Code[31].

\subsubsection{Environmental issues}

Saudi Arabia's General Environmental Law and Rules for Implementation issued on 28 Rajab 1422 H (14 November 2001) set the national agenda on environmental protection, which directly impacts the laboratories. The resource conservation and recovery addresses waste disposal and reduction. The clean air concerns air quality and its effects on human health. The water pollution control deals withthe protection of water quality as well as its improvement.

The main goal of environmental legislation is pollution control and prevention. Pollution prevention, emergency response planning, communication, and community outreach programs must be developed by the institution housing the laboratory facility. Fostering healthy community relations entails going beyond mere regulatory compliance.

\subsubsection{Healthissues}

The Laboratory Standard by Occupational Safety and Health Administration (OSHA) requires institutions that house laboratories to develop their own program to preserve the health and safety of their workers. The institutiondeveloped program, typically called the Hazardous Material Hygiene Plan, must be referred to throughout the design process.

\subsubsection{Safety issues}

The Kingdom of Saudi Arabia has enacted laws to protect elements of basic production, including the labor force. It also issued regulations on protecting the workers from, or compensating them for, injuries or hazards resulting from their work within Saudi Arabia. These tasks of handling safety issues has entrusted to a number of governmental bodies including:

- The Ministry of Labor,

- The General Organization for Social Insurance (GOSI),

- The Ministry of Health,

- The High Commission for Industrial Security,

- The Royal Commission for Jubail and Yanbu, and

- The General Directorate of Civil Defense

The implementation ofPME and OSHA guidelines ensures that thenew or renovated facility promotes, rather than hinders, safe occupancy.

\section{Volume 9 Issue 6, June 2020}




\section{International Journal of Science and Research (IJSR) \\ ISSN: 2319-7064}

ResearchGate Impact Factor (2018): 0.28 | SJIF (2019): 7.583

\subsection{Design Considerations}

Laboratory users involved in the predesign or design phase of a research laboratory project often have pre conceived impressions of what features their future laboratory must have. However, laboratory users often lack experience in laboratory design and so may be unfamiliar with design issues, possible design alternatives, or methods of evaluating those alternatives. The design considerations described in this section are unique to laboratory buildings. While some of the design approaches may increase construction and operation costs, they are critical to the functionality of the facility and the safety of the building users and surrounding community. Users' familiarity with alternative approaches to specific laboratory design issues will most likely lead to a more efficient, cost-effective, flexible, safe, and environmentally appropriate laboratory facility. Although an experienced and knowledgeable design professional can assist in the identification of design issues to consider and can evaluate appropriate alternative approaches to laboratory design, this is not always the case. Even when an experienced and knowledgeable design professional is available, it is advantageous for the user representative and the client team to become informed consumers of the design professional's services.

The design considerations presented here range from those requiring large-scale decisions, such as constructing a new building versus renovating an existing building, through intermediate-scale options, such as floor planning, to smallscale issues, such as laboratory configuration. They also include considerations related to structural as well as Mechanical, Electrical, and Plumbing (MEP) systems (figure2). Administrative policies should be considered throughout, since many institutions have defined practices or standards that affect many design issues. Many of the design considerations are interdependent. Decisions regarding larger-scale issues, which should be made early in the design process, can limit or preclude many of the smaller-scale design decisions. Knowledgeof these dependencies, often provided by the laboratory design professional to the client team, will help streamline the design process and maximize the potential for a costeffective and optimum design solution.

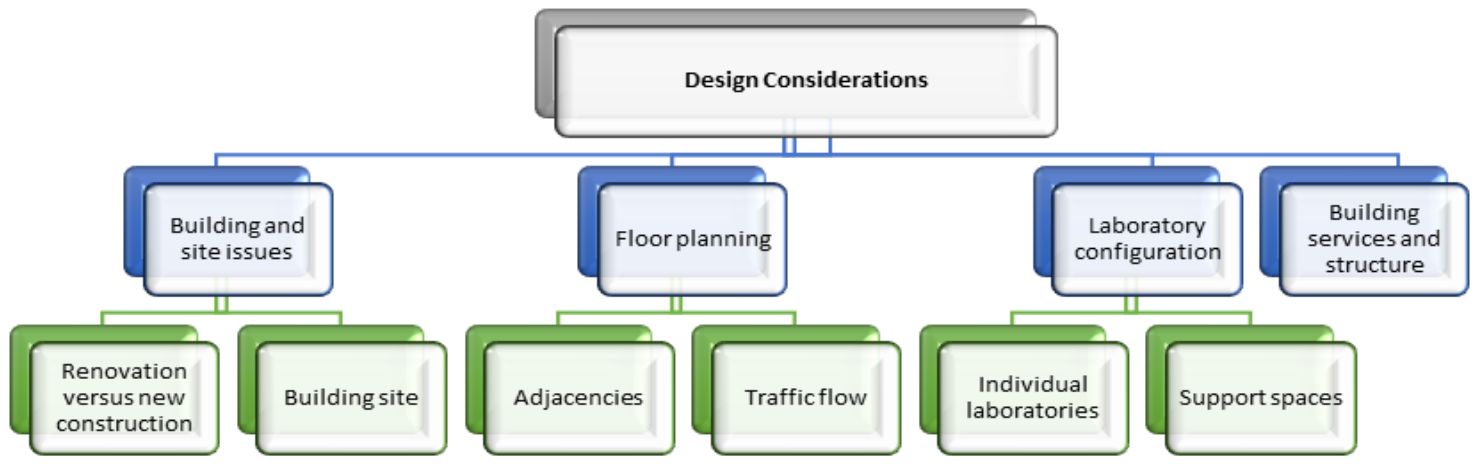

Figure 2: Examples of Large- to Small-Scale Design Considerations

Some of the design considerations include specific alternative approaches. What is acceptable as an alternative in laboratorydesign may differ according to scientific discipline.

Acceptable design alternatives also differ between organizations on the basis oftheir goals, geographic location, governing authorities, and other factors. The goals for a new research laboratory building or renovation should be determined in the early stages of planning as they will influence the development of appropriate design alternatives. Geographic location may influence the acceptability of a particular design alternative. Similarly, the authority of local governing authorities to interpret zoning regulations, building and fire codes, and other local regulations can influence the design of the laboratory facility. Figure 3 illustrate some issues related to building design and site selection.

Choosing between the different alternatives is a complex process that must strike a balance between benefits and costs. The various types of costs include construction, total project, operation, and lifetime costs of the building. When choosing between the different alternatives, other factors besides costs and benefits also need to be considered (seefigure4).

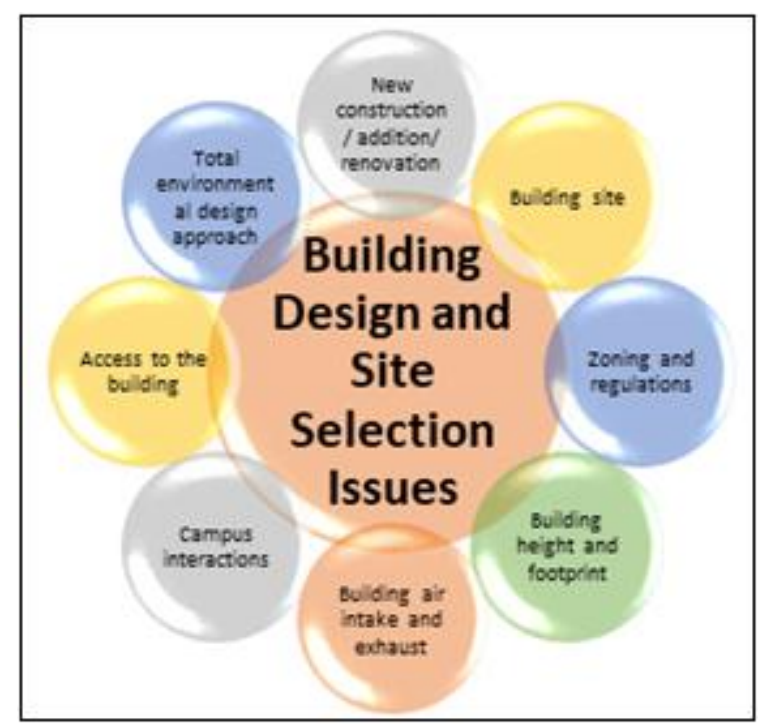

Figure 3: Building Design and Site Selection Issues

Volume 9 Issue 6, June 2020 www.ijsr.net 


\section{International Journal of Science and Research (IJSR) \\ ISSN: 2319-7064}

ResearchGate Impact Factor (2018): 0.28 | SJIF (2019): 7.583

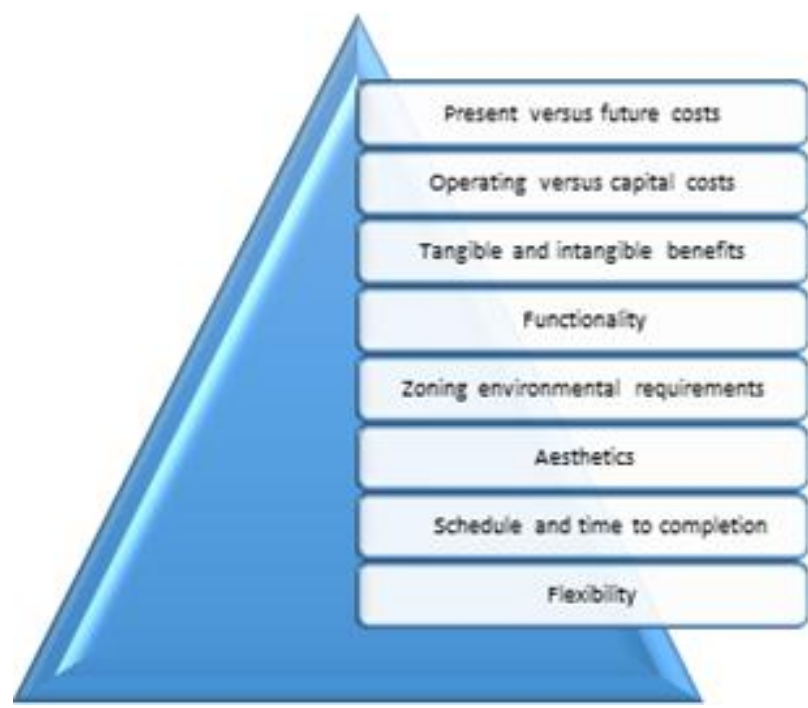

Figure 4: Criteria for Evaluating Design Alternatives

Of all the criteria shown in figure4, flexibility is the one that often pervades all other design considerations. Flexibility, which is also referred to as adaptability, is the ability of a building site, building design, or individual laboratoryto meet both current and unforeseen future needs. Future laboratory additions, renovations, and modifications can be implemented in a cost effective, timely manner, and with less disruption to other users if the laboratory facility is designed to be flexible. Flexibility may come at a modest increase in the initial construction cost; however, because numerous changes will be made to a laboratory over its life time, the cost incurred to design and build a flexible laboratory building will be more than recovered over the lifetime of the laboratory.

\subsection{Laboratory Configuration}

A laboratory with fume hoods, benches, and a sink may be the generic image of a laboratory, but the specific needs of different laboratory activities or scientific disciplines require highly specialized facilities. In general, research laboratories require special ventilation, are utility intensive, and require special furnishings that can withstand instruments, equipment, and potentially caustic and damaging chemicals. As example, in chemical laboratories, a fume hood usually provides the special ventilation needed. In some specialized labs high-efficiency particulate air (HEPA) filters and biosafety cabinets may be required to meet the special ventilation requirements.

It is often more cost-effective to also use standardized laboratory design throughout the laboratory modules for layout, utilities, furnishings, and other features. The standardized or generic laboratory design can be modified to accommodate specific research requirements. Necessary modifications are those that enable laboratory occupants to do their work safely and efficiently. Figure 5 shows some of the laboratory features and furnishings

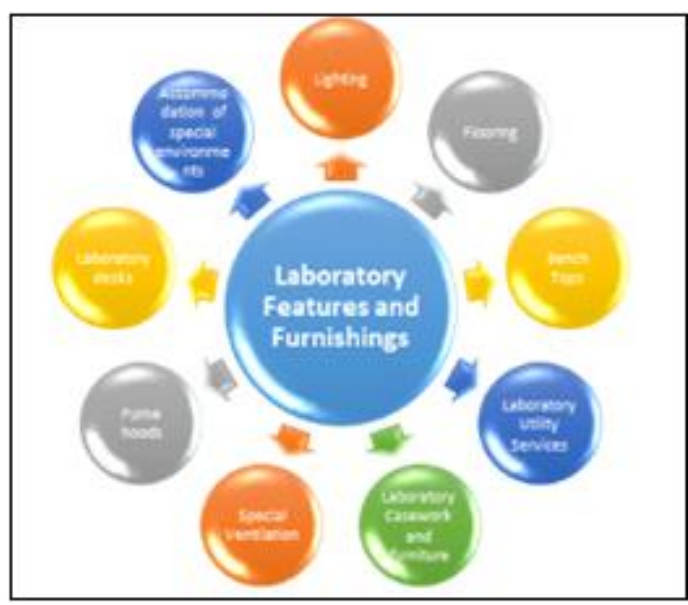

Figure 5: Laboratory Features and Furnishings

\subsection{Research Laboratory Cost Considerations}

Whether in academic institutions, corporations, or government, most scientists and laboratory administrators lack familiarity with the costs of building and/or renovating basic and laboratory specific facilities.

Building costs are commonly divided into two components, construction costs and project costs. Construction costs (brick-and-mortar) typically range from 65 percent to 80 percent of the total project costs. Project costs encompass all other costs incurred by the client (e.g., non-building construction costs, such as utility and construction permits; fees, such as site and materials testing fees; design professionals' fees; contingencies; and move-in activities).

Both construction and project costs for laboratory buildings are traditionally higher than those for other building types. Constructing or renovating laboratory facilities costs more because of their greater complexity, including, for example, requirements for specialized HVAC, mechanical, and electrical systems.

\section{Conclusion}

The factors affecting the Engineering laboratories' construction and renovation vary from project to project depending on the specific technicalities of the proposed laboratory facility project as well as the requirements of the institution. Overall, the general principles expounded by the committee make its recommendations applicable to the construction or renovation of almost any laboratory building. Through investigations, it was concluded that although individual projects differ, there are certain commonalities in successful laboratory construction and renovation projects. These include the right participants and a continuity of personnel; a thorough, well-defined, and thoughtful process; and a broad knowledge of the relevant issues. These common themes have been discussed Technical Issues. The study hasalso targetedexplorationof both internally and externally focused issues.

\section{Acknowledgement}

This work was funded by the Deanship of Scientific Research (DSR), Kink Abdulaziz University, Jeddah, under 


\section{International Journal of Science and Research (IJSR) \\ ISSN: 2319-7064}

ResearchGate Impact Factor (2018): 0.28 | SJIF (2019): 7.583

grant No. (G-1436-829-229). The authors, therefore, acknowledge with thanks DSR technical and financial support.

\section{References}

[1] American Institute of Architects, "Guidelines for Planning and Design of Biomedical Research Laboratory Facilities", Washington, 1999.

[2] Ashbrook, Peter C., and Malcolm M. Renfrew, "Safe Laboratories", New York: Lewis, 1991.

[3] Barona, A, et.al, "Effect of Sudden Variations in Operating Conditions on Biofilter Performance", Biochem. Eng. J. Vol.1, No.22, pp.25, 2004.

[4] Baum, Janet S. "Renovate Your Lab." Chemical Health and Safety, May/June, Vol.2, pp,7-13, 1995.

[5] Bender, R. "Benchmarking Costs for Pharmaceutical Facilities", Pharmaceutical Engineering. Vol. 16, No. 6, pp.28-34, 1996.

[6] C.R. Avery, S.G. Burrow, P.H. Mellor, "Electrical Generation and Distribution for the more Electric Aircraft", UPEC Universities Power Engineering Conference, Sept. 2007, pp. 1007-1012.

[7] Di Berardinus, Louis, et.al, "Guidelines for Laboratory Design”, New York: John Wiley \& Sons, 1993.

[8] Elı'as, A, et.al, "Evaluation of a Packing Material for the Biodegradation of $\mathrm{H}_{2} \mathrm{~S}$ and Product Analysis", Process Biochem. Vol.37, pp.813, 2005.

[9] Foster, B. L. "Laboratory Safety and Management: A Handbook for Teaching Assistants", Morgantown, WV, 2004.

[10] Gramling R, Nash J, Siren K, Eaton C, Culpepper L., "Family Physician Self-Efficacy with Screening for Inherited Cancer Risk", Ann Fam Med Vol.2, pp.130132, 2004.

[11] Griffin, Brian B. "Laboratory Design Guide", Boston: Architectural Press, 1998.

[12]Hill, R. H. "Changing the Way Chemists Think About Safety", Chem. Health Safety, Vol.11, No.3, pp.5, 2004.

[13] IEC Technical Specification, "Effects of Current on Human beings and Livestock part 2: Special Aspects", $3^{\text {rd }}$ ed., Geneva, Switzerland: International Electrotechnical Commission, 2007.

[14] IEEE, "National Electric Safety Code", C2-2012

[15]J.F. Gieras, "Recent Advancements in Aircraft Generators", IEEE International Electric Machines and Drives Conference May 2009, pp. 553-554.

[16] Mayer, Leonard, "Design and Planning of Research and Clinical Laboratory Facilities", New York: John Wiley \& Sons, 1995.

[17] National Institutes of Health, "Research Laboratory: NIH Design Policies and Guidelines", 1998.

[18] National Research Council, "Guide for the Care and Use of Laboratory Animals" Washington, D.C. National Academy Press, 1996.

[19]NFPA 70E, "Standard for Electrical Safety in the Workplace", 2012.

[20]Piller, Charles. "Biomedical Research and the Nightmare in Laurel Heights", New York: Basic Books, 1991.

[21]Rich EC, Burke W, Heaton CJ, et. All.,
"Reconsidering the Family History in Primary Care", J Gen Intern Med Vol.19, pp.273-280, 2004.

[22] Richmond, J.Y., and R.W. McKinney, "Biosafety in Microbiological and Biomedical Laboratories", $3^{\text {rd }}$ Edition. U.S. Department of Health and Human Services, Washington, D.C, 1993.

[23] Stark, and Stanley, "Research Facilities of the Future", New York: New York Academy of Sciences, 1994.

[24] Stroud, L. M, "Science Laboratory Safety Facilitators Manual", 2006

[25] Suther S, Goodson P. "Barriers to the Provision of Genetic Services by Primary Care Physicians: a Systematic Review of the Literature", Genet Med Vol.5, pp.70-76, 2003.

[26] T. Lanzisero, “Applied Safety Science and Engineering Techniques (ASSET): Taking HBSE to the Next Level", IEEE of International Symposium on Product Compliance Engineering, 2010.

[27] T. Lanzisero, "ASSET: The Evolution of Hazard based Safety Engineering into the Framework of a Safety Management Process", IEEE of International Symposium on Product Compliance Engineering, 2011.

[28] U.S. Chemical Safety Board, "CSB to Investigate Laboratory Explosion at Texas Tech University Chemistry Department", 2010.

[29] Walsh, S.P., White, K.M., Young, R.M., "Overconnected A Qualitative Exploration of the Relationship between Australia Youth and their Mobile Phones", Journal of Adolescence, Vol.31, pp.77-92, 2008.

[30] Wiediger, S.D. and Hutchinson, J.S., "The Significance of Accurate Self-Assessment in Understanding of Chemical Concepts", J Chem Educ, Vol.79, No. 1, pp.120-124, 2002.

[31] Wikipedia, Uniform Building Code", http://en.wikipedia.org/wiki/Uniform_Building _Code [Accessed on Sept. 2014]

[32] Williams, J. H., "Improving Safety Leadership: Using Industrial/Organizational Psychology to Enhance Safety Performance", Professional Safety, Vol.47, No. 4, pp.43-47, 2003

[33] Williams, J.H., Geller, E.S., "Behavior-based Intervention for Occupational Safety: Critical Impact of Social Comparison Feedback", Journal of Safety Research, Vol. 31, No. 3, pp. 135-142, 2000.

[34] Wu, T. -C. "The validity and Reliability of Safety Leadership Scale in Universities of Taiwan", International Journal of Technology and Engineering Education, Vol.2, No.1, pp.27-42, 2005.

[35] Wu, T. -C., Li, C. -C., \& Shu, Y.-H. "Measuring Safety Culture in Departments of Electrical and Electronic Engineering at Universities", $10^{\text {th }}$ UICEE Annual Conference on Engineering Education pp.229-232, 2005.

[36] Wu, T.-C., Liu, C.-W., Lu, M.-C., "Safety Climate in University and College Laboratories: Impact of Organizational and Individual Factors", Journal of Safety Research, Vol.38, pp.91-102, 2007.

[37]Zhu, R.-R, "Research Methods for Social Science and Data Analysis", Taipei, Yang-Chih Book Co., 2002.

[38]Zohar, D., "The Effects of Leadership Dimensions, Safety Climate, and Priorities on Minor Injuries in

\section{Volume 9 Issue 6, June 2020}




\section{International Journal of Science and Research (IJSR) \\ ISSN: 2319-7064}

ResearchGate Impact Factor (2018): 0.28 | SJIF (2019): 7.583

Work Groups", Journal of Organizational Behavior, Vol.23, pp.75-92, 2002.

\section{Author Profile}

Prof. Mostafa Abdel-BaryEbrahim received the B.Sc. and M.Sc. degrees in Civil Engineering from Faculty of Engineering, Assuit University in 1986 and 1992, respectively. During 1995-1998, he stayed in Institute of Geodesy, Innsbruck University, Austria to study the evaluation and application of digital close range photogrammetry for Ph.D. He has been awarded his Ph.D. degree on 1998. He is now working as full professor at King AbdulAziz University, Kingdom of Saudi Arabia.

Volume 9 Issue 6, June 2020 www.ijsr.net 